\title{
15. COVID-19 border policies create problems for African trade and economic pain for communities
}

\section{Antoine Bouët and David Laborde}

The COVID-19 pandemic has triggered a range of border controls in countries around the world to curb the spread of the disease. In Africa, these moves have interrupted progress toward economic integration. The African Continental Free Trade Area (AfCFTA), for example, was supposed to establish continentwide free movement of goods starting on July 1. Now, the African Union Commission has proposed postponing the launch until January 1, 2021. In addition, trade restrictions implemented in Africa and elsewhere in response to the pandemic are fueling fears of a new food crisis on the continent (see IFPRI's tracking of export restrictions).

Across Africa, pandemic-related border controls are having many economic impacts, large and small. Here, we examine these impacts and suggest ways to soften the blow to affected people and communities.

Most African countries have closed land borders to travelers, while still allowing freight to pass under tighter controls, which sometimes allows the movement of only agricultural and food products. Over one 11-day period in March, 24 African countries imposed such measures on land borders (Figure 1). Almost all these countries have also suspended the arrival of international flights, at least from countries particularly affected by the virus. Many governments have also imposed curfews.

The Democratic Republic of the Congo, Kenya, Liberia, and Namibia chose a different path: the entry of people at border posts is subject to temperature control and testing, followed by hospitalization and/or quarantine if necessary.

These measures have been adopted to protect public health, but their economic consequences could be significant. Stricter sanitary border controls on the transport of products are likely to slow intra-African trade. In addition, prohibiting people from crossing borders stops one means of informal trade, widely practiced in Africa and often the main source of income for a family. Informal trade accounts for a significant share of recorded trade: for example, between $15 \%$ and $30 \%$ of official exports in Uganda.

The consequences of these measures for intracontinental trade are still unclear due to a lack of recent data. Thus far, statistics compiled by the Food Security and Nutrition Working Group (weekly data collected at border posts in East Africa - the only data available through the end of March) do not indicate a decrease in cross-border agricultural trade. Most of the border closures took place in the second half of March, so it is too early to tell if data capture any effects. And only five countries (Djibouti, Ethiopia, Rwanda, Sudan, Uganda) implemented border closures in East Africa during this period. 


\section{FIGURE 1 Closure of land borders in Africa, March 2020}

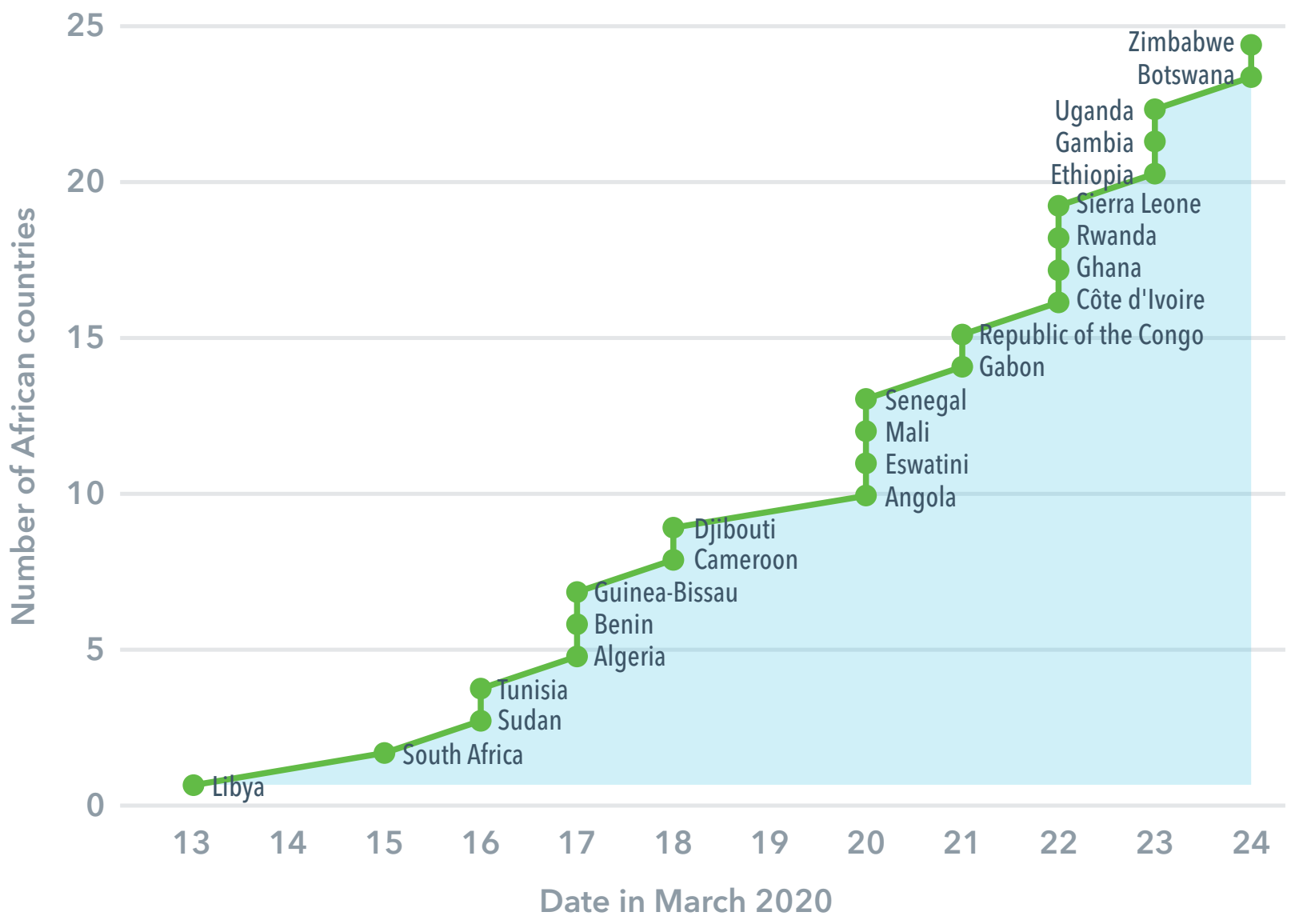

Source: Authors' elaboration from websites of US embassies in Africa and from al Jazeera.

\section{Problems with border policies}

Most border closures have been imposed with little clear knowledge of what is happening on the ground. For example, in West Africa, because of daytime heat, fresh produce, meat, and other perishable products are usually transported at night. Yet curfews make this practice impossible. Mandating more thorough health checks without adding necessary personnel also increases transport times. Health check delays and curfews are likely to cause significant waste and loss of products in West Africa, according to an interview with Brahima Cissé, a trade analyst with the Permanent Interstate Committee for Drought Control in the Sahel (CILSS).

Border restrictions on travel can be particularly costly for livestock producers practicing transhumance - seasonally moving livestock between grazing grounds. This occurs between Sahelian countries including Burkina Faso, Mali, and others to coastal countries such as Benin and Côte d'lvoire; and between Kenya and Uganda. Beyond their immediate economic costs, these measures threaten the basic mode of operation of pastoral agriculture. 
Travel restrictions can also make access to inputs such as fertilizers or pesticides more difficult.

The introduction of exceptional measures provides a breeding ground for the abuse of power. In many parts of Africa, it is common practice for law enforcement officials to set up checkpoints along trade corridors to collect bribes. As recent measures have slowed road transport in West Africa, this predatory behavior has increased in intensity: according to Cissé, bribe collection has increased by $30 \%$ per truck along these corridors since March.

Most of these measures were imposed with little warning, taking local populations by surprise and leaving them to contend with the fallout. With informal trade interrupted, many people have had little opportunity to find alternative livelihoods. For many families, the absence of income for even several consecutive days can have devastating effects on poverty and food security.

There has also been little international or regional coordination of these border-related decisions. For example, curfew times often vary between neighboring countries, compounding their economic impacts.

Finally, such measures may interrupt international technical assistance (health and/or food aid), imposing significant economic, public health, and other costs.

\section{Potential solutions}

To address these hardships, governments should provide ample safety nets to those affected, for example, informal traders making their living from cross-border trade. But safety nets are costly and difficult to design. How to set up these transfers in a period of confinement (especially in the absence of possible digitalization of payments in some countries)? How can measures be put in place that take into account the specific vulnerability and role of women?

The World Health Organization (WHO) has often expressed reservations about the border crossing bans and their role in protecting public health. They increase the likelihood that people will cross borders through places not covered by customs authorities and evade health checks. The WHO is also concerned that governments might avoid publicly acknowledging an outbreak in order to avoid having their citizens targeted by other countries' trade and travel restrictions.

Border checkpoints should be set up to provide health checks and screening, possibly followed by quarantine and/or hospitalization for the infected. Such a system can provide important health information to the population and improve the distribution of protective equipment, soap and disinfection equipment, and access to water. In the East African Community (EAC: Burundi, Kenya, Rwanda, South Sudan, Tanzania, Uganda), nine mobile laboratories have recently been deployed to provide systematic testing, particularly along the northern border between Uganda and Kenya.

Physical distancing requirements at border crossings may also reduce the spread of the virus. But this of course requires supplementing the teams of customs officers working at border stations, so as not to slow down cross-border trade too much. 
To reduce the costs for farmers and transporters of agricultural and food products, governments should reconsider curfews, which hurt the transport of perishable products. In terms of intra-African trade policy, import taxes on agricultural and food products should be reduced to compensate for higher transport costs. A suspension of export bans on these same products should also be considered.

New border restriction measures should be announced in advance in order to allow people to adapt as best as possible. Countries should also coordinate their policies to allow for exchanges of information on the spread of the virus and responses. The WHO Africa Regional Office and the Inter-African Bureau for Animal Resources can help in this regard. Regional Economic Communities can also play an important role. In addition to the EAC, the Economic Community of West African States (ECOWAS) is studying a plan of action including the lifting of all land border and port restrictions on the free movement of agricultural inputs, including fertilizers and pesticides, and the promotion of social safety net projects for food and nutrition.

Finally, countries should not let the pandemic stop progress toward economic integration. The need for the AfCFTA has been reaffirmed by influential figures such as Presidents Paul Kagame of Rwanda and Cyril Ramaphosa of South Africa, as it can provide not only a solid basis for long-term economic development, but also a means of effectively fighting future pandemics by facilitating the cross-border trade of food and medical goods. Virtual negotiations could begin in the coming days to set a new start date, possibly before January 1.

Defining coherent policies in health and economic terms in the face of a pandemic such as COVID-19 is a particularly complicated exercise. It already seems to be very difficult in rich countries with significant financial resources and strong institutions. It is obviously even more difficult in poor countries, where financial resources are very limited and institutions are sometimes weak. Policies adapted for countries with strong institutions can be inappropriate, or even harmful, in countries with weaker ones. For example, as we have seen, imposing stricter health controls along trade corridors can increase the predatory behavior of local control authorities and make the situation worse. The international community must therefore help these countries to take into account the institutional environment when implementing these policies.

Originally published May 12, 2020. 